Methods With proposed changes in the Irish Health Services and the development of commissioning services/service provision in the Community Healthcare Organisation/Hospital Group Model, the most effective model of care is a central governance unit i.e. WHWU with areas covered geographically by defined Area/collaborative service delivery units, this is referred to as a 'hub and spoke' model. The structure of each hub includes occupational health physician services, occupational health nursing services, employee assistance programmes, rehabilitation services, health promotion, health and safety, and the provision of governance and support.

The targets for the area/collaborative service delivery units, 'hub and spoke' model will be exactly as described by the Healthy Staff, Better Care for Patients. www.dh.gov.uk 2011.

Result This model of care will be implemented over Q.2 2017 to Q2 2018

In order to meet these service needs there must be integration with local health and Safety, stress management services, rehabilitation services, health and wellbeing and counselling services.

- Prevention - of ill health caused or exacerbated by work

- Timely intervention- easy and early treatment for the main cause of sickness absence.

- Rehabilitation - to help staff stay at work or return to work after illness

- Health Assessments for work- to help manage attendance, retirement and related matters

- Promotion of health and well being - using work as a means to improve health and well being and using the workplace to promote health

- Teaching and training - encouraging staff and managers to support staff health and well-being.

Discussion The role of the Workplace Health and Wellbeing is to progress the 'Hub and Spoke' model and to evaluate the effectiveness.

\section{CLEANING AND DISINFECTION IN HOME HEALTHCARE: INTEGRATING QUALITATIVE AND QUANTITATIVE METHODS TO ASSESS CAREGIVERS' EXPOSURE TO CLEANING AND DISINFECTION PRODUCTS}

\begin{abstract}
${ }^{1}$ Pia Markkanen*, ${ }^{1}$ Margaret Quinn, ${ }^{2}$ Nancy Goodyear* ${ }^{1}$ Catherine Galligan, ${ }^{1}$ David Kriebel, ${ }^{1}$ Susan Sama, ${ }^{1}$ Rebecca Gore, ${ }^{1} J o h n$ Lindberg, ${ }^{2}$ Christian Beato-Melendez, ${ }^{1}$ Nicole Karlsson, ${ }^{2}$ Hagir Mohamed, ${ }^{1}$ Noor Sheikh, ${ }^{3}$ Alexis Parker-Vega* . ${ }^{1}$ Department of Public Health, University of Massachusetts Lowell, Lowell, USA; ${ }^{2}$ Department of Biomedical and Nutritional Sciences, University of Massachusetts Lowell, Lowell, USA; ${ }^{3}$ Office of Environment, Health and Safety, University of California San Francisco, San Francisco, USA
\end{abstract}

\subsection{6/oemed-2018-ICOHabstracts.996}

Introduction In the United States, home care (HC) aide is one of the fastest growing jobs. Aides perform both personal care and cleaning and disinfection (C and D) tasks in the clients' homes. There is clear scientific evidence of asthma and other respiratory effects with $\mathrm{C}$ and $\mathrm{D}$ work. This presentation demonstrates how mixed research methods assessed the nature of $\mathrm{C}$ and D work and health-related exposures in HC.

Methods The Safe Home Care Project conducted 9 focus groups comprising $80 \mathrm{HC}$ aides and 5 in-depth interviews with HC employers' and workers' representatives. All focus groups and interviews were audio-recorded and transcribed verbatim. Computer-assisted thematic analysis of all transcripts was conducted. The results informed the development of (i) the microbiology field study in 46 seniors' homes to measure micro-organisms and soil on common household surfaces and how effectively 'green' and bleach-containing products cleaned these surfaces, and (ii) the laboratory study to measure airborne $\mathrm{C}$ and D product exposures among HC aides $(n=20)$ who performed $\mathrm{C}$ and $\mathrm{D}$ tasks in a simulated bathroom with 4 different products.

Result HC aides sanitise bathrooms and kitchens frequently. Bleach-containing products are commonly applied and HC clients mostly decide which $\mathrm{C}$ and D products are used. The microbiology study showed that both 'green' and bleach-containing products removed micro-organisms on tested surfaces. The laboratory study showed that the bleach-containing cleaning product generated high airborne chlorine exposures: over $60 \%$ of the aides exceeded $1 \mathrm{ppm}$ for chlorine - a permissible exposure limit of the US Occupational Safety and Health Administration.

Discussion Mixed methods research techniques provide complementary data for assessing and characterising $\mathrm{C}$ and $\mathrm{D}$ exposures in HC. Use of bleach-containing products can generate high airborne chlorine exposures. Chlorine is a respiratory irritant. It seems prudent to limit the unnecessary use of bleach in HC and carefully discern - on a client-by-client basis - whether bleach is needed for infection prevention.

\section{OCCUPATIONAL HEALTH AND SAFETY ISSUES OF ETHICAL DILEMMAS FACED BY NURSES IN CLINICAL PRACTICE SETTINGS: A QUALITATIVE STUDY}

${ }^{1} \mathrm{C}$ Caux*, ${ }^{1} \mathrm{~F}$ Dupuis, ${ }^{2} \mathrm{~K}$ Lechasseur, ${ }^{3} \mathrm{~J}$ Lecomte. 'Université de Montréal, Canada; ${ }^{2}$ Université Laval, Québec, Canada; ${ }^{3}$ CIUSS Centre-Sud-de-l'̂le-de-Montréal, Canada

\subsection{6/oemed-2018-ICOHabstracts.997}

Introduction During their practice, nurses regularly encounter ethical dilemmas. The sources of these dilemmas, according to the literature, seem mainly related to clinical practice settings, such as emergency, intensive, palliative, oncology, etc. However, as part of a graduate clinical ethics course for nurses, we also noticed that the sources of nurse ethical dilemmas seem to be very much related to occupational safety and health $(\mathrm{OSH})$ considerations as opposed to clinical situations. This research aimed to highlight these sources of ethical dilemmas that can be attributed to contexts and aspects other than those found in the literature, particularly those related to OSH.

Methods Ethical dilemmas were assessed qualitatively by analysing 250 written descriptions presented by students in the graduate clinical ethics course for nurses. Each description was analysed using the continuous comparison technique in order to produce an emergent model, which reconstructed the nurses' representations of ethical dilemmas pertaining to $\mathrm{OSH}$. Results The results provide a much broader picture of the ethical dilemmas faced by nurses. The model shows that the majority of ethical dilemmas described has underlying dynamics related to OSH. They described ethical dilemmas arising from an explicit risk to their physical or psychological health such as exposure to biological agents, bullying or threats from the patient's family. Moreover, many of the ethical dilemmas are expressed by the nurses primarily in terms of consequences for herself and not for the patient.

Conclusion This model emphasises that OSH issues have a significant impact on ethical dilemmas experienced by nurses. Consequently, these issues should be part of the discussions regarding ethical climate in nursing management and education. 